\title{
Contribuições de oficinas pedagógicas na formação do interlocutor da educação permanente em saúde
}

\author{
Vivian do Prado Martins ${ }^{1}$, Letícia Lopes Dorneles ${ }^{2}$, Caroline Silva Morelato Coloni ${ }^{3}$, \\ Andréa Bernardes ${ }^{4}$, Rosangela Andrade Aukar de Camargo ${ }^{5}$
}

\section{RESUMO}

Objetivou-se identificar as contribuições de oficinas pedagógicas na formação do interlocutor da Educação Permanente em Saúde. Estudo longitudinal, realizado no período de 2015 a 2017, com abordagem qualitativa, do qual participaram 15 interlocutores do Núcleo de Educação Permanente em Saúde, representantes de municípios do nordeste paulista. As informações foram coletadas por questionário sociodemográfico e grupo focal; tais informações foram transcritas, submetidas à análise de conteúdo e interpretadas à luz da Pedagogia Crítica Freiriana. Configuraram-se duas categorias: "Do tempo do verbalismo e ativismo ao ato consciente na EPS" e "Da obstinação do método tradicional de ensino às ações em EPS com método ativo". O ciclo de atividades, fundamentado na ação-reflexão-ação, vivenciado nas oficinas pedagógicas, contribuiu para compreensão dos conceitos introdutórios e pressupostos do método ativo de aprendizagem na construção de espaços coletivos de educação, em contraposição ao método tradicional de ensino.

Descritores: Educação Continuada; Aprendizagem; Política de Saúde; Recursos Humanos em Saúde; Educação em Enfermagem.

\footnotetext{
${ }^{1}$ Enfermeira. Residente em Oncologia pelo programa de Residência Multiprofissional em Atenção ao Câncer do Hospital das Clínicas da Faculdade de Medicina de Ribeirão Preto da Universidade de São Paulo. Ribeirão Preto, SP, Brasil. E-mail: vivian.martins@usp.br.

2 Enfermeira, Mestre em Enfermagem em Saúde Pública. Docente do Departamento Materno-infantil e Saúde Pública da Escola de Enfermagem de Ribeirão Preto da Universidade de São Paulo. Ribeirão Preto, SP, Brasil. E-mail: leticia dorneles@usp.br.

${ }^{3}$ Enfermeira. Discente do Programa de Pós-Graduação em Enfermagem em Saúde Pública, nível Mestrado, da Escola de Enfermagem de Ribeirão Preto da Universidade de São Paulo. Ribeirão Preto, SP, Brasil. E-mail: caroline.morelato@usp.br.

${ }^{4}$ Enfermeira, Doutora em Enfermagem Fundamental. Professora Associada da Escola de Enfermagem de Ribeirão Preto da Universidade de São Paulo. Ribeirão Preto, SP, Brasil. E-mail: andreab@eerp.usp.br.

${ }^{5}$ Enfermeira, Doutora em Enfermagem Psiquiátrica. Professora Doutora da Escola de Enfermagem de Ribeirão Preto da Universidade de São Paulo. Ribeirão Preto, SP, Brasil. E-mail: rcarmargo@usp.br.
}

Artigo recebido: 07/11/2017.

Artigo aprovado: 14/08/2018.

Artigo publicado: 31/12/2018.

\section{Como citar esse artigo:}

Martins VP, Dorneles LL, Coloni CSM, Bernardes A, Camargo RAA. Contribuições de oficinas pedagógicas na formação do interlocutor da educação permanente em saúde. Rev. Eletr. Enf. [Internet]. 2018 [acesso em: ];20:v20a47. Disponível em: https://doi.org/10.5216/ree.v20.50148. 


\section{INTRODUÇÃO}

A educação permanente de profissionais que atuam na área da saúde é um desafio que busca articular saberes e práticas, ampliar/extrapolar o conhecimento técnico científico e, nesse sentido, tem mobilizado as instituições de ensino e serviços de saúde ${ }^{(1)}$. Revisão integrativa realizada no Irã, que analisou os resultados das parcerias entre essas instituições, encontrou benefícios mútuos, bem como constatou que o trabalho sinérgico tem empoderado os trabalhadores e produzido novos conhecimentos para os avanços da prática assistencial na saúde ${ }^{(2)}$.

Esse mesmo fenômeno pode ser observado com resultados promissores ${ }^{(3)}$ também no Brasil onde, da mesma forma, a Educação Permanente em Saúde (EPS) tornou-se uma política pública, por vezes encampando essa cooperação. Instituída em 2004, a Política Nacional de Educação Permanente em Saúde (PNEPS) caracterizase pela busca da transformação do processo de trabalho de cada unidade do Sistema Único de Saúde (SUS). Consiste em um processo educativo a ser realizado coletivamente pela própria equipe de saúde e parceiros da academia, de forma consciente, responsável e comprometida com a integralidade do cuidado em saúde da comunidade ${ }^{(4)}$.

Para disseminação e implementação da PNEPS no âmbito do Estado de São Paulo, região sudeste do Brasil, os Departamentos Regionais de Saúde (DRS), por meio de seus Centros de Desenvolvimento e Qualificação de Recursos Humanos (CDQ), constituíram os Núcleos de Educação Permanente Regionais (NEPR). Nesses núcleos, participam interlocutores nomeados pelos municípios que compõem a região de saúde, sendo eles os responsáveis pela facilitação do processo de EPS em seu município de origem. Diante disso, é inegável a importância da qualificação dos interlocutores, foco deste estudo, uma vez que são eles os porta-vozes da EPS em seus respectivos municípios, além de oferecerem suporte e apoio para o desenvolvimento de ações educativas e reflexão crítica dos processos de trabalho e da situação de saúde nos municípios que representam ${ }^{(4-6)}$.

Isso significa que, para o desenvolvimento e construção do conhecimento desses interlocutores, se faz necessária a existência de espaços de vivências fundamentadas nas metodologias ativas de aprendizagem, contextualizadas e participativas, como preconiza a PNEPS ${ }^{(7)}$.

Nessa perspectiva, esta pesquisa optou por realizar Oficinas Pedagógicas (OP) com interlocutores uma vez que se alinham aos pressupostos da EPS na promoção de práticas educativas para a reflexão coletiva da realidade de saúde, além de identificarem as potencialidades de seus resultados.

As Oficinas Pedagógicas, fundamentadas no pensamento de Paulo Freire ${ }^{(8-10)}$ constituem-se em espaços dinâmicos de construção do conhecimento que, por meio da promoção do diálogo, fomentam um processo criativo de aprendizagem coletiva e transformação da realidade. As OP são compreendidas como um tempoespaço descontraído de trocas de experiências e formação de vínculo que buscam como processo de aprendizagem a reflexão do pensar, sentir e agir, proporcionando ao grupo a análise da realidade e a construção coletiva do saber. Em outras palavras, numa oficina ocorrem apropriação, construção e produção de conhecimentos teóricos e práticos, de forma ativa e reflexiva. Decorrem, principalmente, do conhecimento prévio, das habilidades, dos interesses, das necessidades, dos valores e dos julgamentos dos participantes ${ }^{(10)}$.

$\mathrm{Na}$ literatura, verificou-se a realização de oficinas na educação popular, na saúde mental e na construção da prática política, caracterizadas pela valorização do compartilhamento de ideias a partir do diálogo ${ }^{(11-13)}$. 
Entretanto, compreende-se que as publicações são escassas sobre essa intervenção e, portanto, não oferecem subsídios suficientes sobre seu planejamento pedagógico e respectivos resultados. Nesse sentido, dada a importância dessa intervenção educativa para a disseminação e fortalecimento da PNEPS no contexto do SUS, esse estudo objetivou identificar as contribuições de oficinas pedagógicas na formação do interlocutor da Educação Permanente em Saúde.

\section{MÉTODOS}

Trata-se de um estudo longitudinal com abordagem qualitativa, realizado entre 2015 e 2017, numa cidade do interior paulista, que tem população estimada de mais de 100.000 habitantes, e referência em saúde para 18 municípios da região nordeste do Estado de São Paulo e todo Brasil. É fruto da parceria entre uma instituição pública de ensino superior e o DRS, estrutura que congrega as atividades da gestão estadual do SUS e que abriga as reuniões do NEPR, local em que foi desenvolvida a pesquisa.

Os participantes da pesquisa foram 15 interlocutores da educação permanente, profissionais da saúde que são representantes de instituições de saúde da região local do estudo. Para que participassem da pesquisa, os interlocutores deveriam estar há pelo menos seis meses no Núcleo de Educação Permanente (NEP) e ter frequência mínima de $70 \%$ nas OP.

O planejamento das OP realizadas pelas pesquisadoras foi fundamentado no referencial da Pedagogia Crítica Freiriana como forma de emancipação social|(14). As atividades estruturaram-se com a seguinte sequência: problematização da realidade e identificação das necessidades de aprendizagem, por meios dos quais foram eleitos os temas geradores; análise teórica da situação-problema com propostas de solução; e atividade de dispersão realizada pelos interlocutores no cotidiano de suas instituições de saúde.

$\mathrm{Na}$ fase de problematização da realidade, durante as discussões em conjunto com os interlocutores, encontraram-se quatro temas sobre EPS que necessitavam ser trabalhados. A fim de encontrar soluções e construir coletivamente novos conhecimentos para os problemas relacionados a esses temas, foram desenvolvidas seis OP: uma OP para o $1^{\circ}$ e $2^{\circ}$ temas e duas OP para o $3^{\circ}$ e 4 , , uma vez que foram considerados mais complexos. As oficinas foram agendadas e coordenadas pelos pesquisadores, com intervalo de até dois meses entre elas. Apresentam-se no Quadro 1 os problemas identificados, as necessidades de aprendizagem dos interlocutores em relação aos problemas encontrados e as atividades de dispersão que foram desenvolvidas em grupos pelos participantes das oficinas em seus locais de trabalho, a fim de se obter a aprendizagem significativa e aplicada a realidade das instituições. Todas as OP foram fundamentadas em artigos científicos sobre o tema gerador, que eram enviados antecipadamente aos participantes para leitura prévia.

As OP foram planejadas alternando o método de trabalho independente, com exposição dialogada, elaboração conjunta com o mediador e o trabalho em grupo, embasados pela abordagem crítica e reflexiva ${ }^{(14)} \mathrm{em}$ todos os momentos. As estratégias diversificadas contemplaram discussão de vídeos, construção de mapas conceituais, esquetes teatrais e estudos de caso. A escolha do método e da estratégia teve como foco a sensibilização do interlocutor para o diálogo sobre o conhecimento prévio, trocas de experiências, discussão do referencial teórico e possíveis articulações com a prática, sustentada por artigo científico. 
Quadro 1: Temas das oficinas pedagógicas - Município do nordeste paulista - 2015 a 2017.

\begin{tabular}{|c|c|c|c|}
\hline OFICINA & PROBLEMAS IDENTIFICADOS & $\begin{array}{l}\text { NECESSIDADES DE } \\
\text { APRENDIZAGEM }\end{array}$ & ATIVIDADE DE DISPERSÃO \\
\hline OFICINA 1 & $\begin{array}{l}\text { 10 tema - Participantes confundem } \\
\text { o propósito da educação } \\
\text { permanente e da educação } \\
\text { continuada no cotidiano das } \\
\text { instituições de saúde } \\
\text { - Qual a diferença de educação } \\
\text { permanente e educação } \\
\text { continuada? } \\
\text { - Como elas se aplicam no meu } \\
\text { local de trabalho? }\end{array}$ & $\begin{array}{l}\text { - Contextualizar o conceito de } \\
\text { educação permanente em saúde, } \\
\text { educação continuada, seus } \\
\text { pressupostos e suas } \\
\text { características } \\
\text { - Refletir sobre a trajetória } \\
\text { histórica e cultural da educação } \\
\text { brasileira }\end{array}$ & $\begin{array}{l}\text { - Elaborar um diagnóstico da } \\
\text { situação da instituição de saúde } \\
\text { das atividades educativas } \\
\text { desenvolvidas e como são vistas } \\
\text { pelos trabalhadores e gestores }\end{array}$ \\
\hline OFICINA 2 & $\begin{array}{l}\text { 20 tema - Participantes reconhecem } \\
\text { as limitações do método tradicional } \\
\text { de ensino, porém não conseguem } \\
\text { compreender como se estabelece o } \\
\text { método ativo de aprendizagem } \\
\text { - Como e por que o método ativo } \\
\text { de aprendizagem é mais produtivo } \\
\text { que o método tradicional? }\end{array}$ & $\begin{array}{l}\text { - Compreender os fundamentos } \\
\text { do método tradicional e do } \\
\text { método ativo de aprendizagem, e } \\
\text { como eles se articulam à } \\
\text { educação permanente em saúde }\end{array}$ & $\begin{array}{l}\text { - Construir apresentações } \\
\text { vivenciadas pelos participantes } \\
\text { nas instituições de saúde para } \\
\text { serem compartilhadas e } \\
\text { discutidas }\end{array}$ \\
\hline $\begin{array}{l}\text { OFICINAS } \\
\text { 3 E } 4\end{array}$ & $\begin{array}{l}\text { 3o tema - Participantes desejam } \\
\text { aprofundar a compreensão sobre o } \\
\text { processo de ensino e aprendizagem } \\
\text { - Como se aprende e como se } \\
\text { ensina? } \\
\text { - Quais são as contribuições de } \\
\text { Piaget e Paulo Freire para a } \\
\text { educação? }\end{array}$ & $\begin{array}{l}\text { - Discutir sobre as contribuições } \\
\text { de Jean Piaget para a } \\
\text { compreensão da construção do } \\
\text { conhecimento } \\
\text { - Refletir sobre as contribuições } \\
\text { de Paulo Freire e o método da } \\
\text { problematização Compreender o } \\
\text { Arco de Charles Maguerez }\end{array}$ & $\begin{array}{l}\text { - Construir uma ação educativa } \\
\text { com base no referencial teórico, } \\
\text { criar uma apresentação e } \\
\text { compartilhar com o grupo para } \\
\text { discussão }\end{array}$ \\
\hline $\begin{array}{l}\text { OFICINAS } \\
5 \text { E } 6\end{array}$ & $\begin{array}{l}\text { 40 tema - Participantes expressam } \\
\text { dificuldade para planejar as ações } \\
\text { de educação permanente e } \\
\text { educação continuada } \\
\text { - Como planejar as atividades de } \\
\text { educação permanente e educação } \\
\text { continuada? }\end{array}$ & $\begin{array}{l}\text { - Compreender as etapas do } \\
\text { planejamento de atividades } \\
\text { educativas }\end{array}$ & $\begin{array}{l}\text { - Elaborar um planejamento das } \\
\text { ações prevista de educação para } \\
\text { a instituição, elaborar a } \\
\text { apresentação e compartilhar } \\
\text { com o grupo para discussão }\end{array}$ \\
\hline
\end{tabular}

Para a coleta de dados foram utilizadas as informações provenientes de um questionário sociodemográfico construído pelos pesquisadores. Aos que concordaram participar da pesquisa, entregamos o instrumento de coleta de dados para que fosse preenchido e o Termo de Consentimento Livre e Esclarecido (TCLE) para leitura e assinatura. A caracterização do perfil dos participantes foi analisada mediante estatística descritiva e por meio de um Grupo Focal (GF) ${ }^{(15)}$ constituído após a última oficina que foi gravada e, posteriormente, teve suas informações transcritas e arquivadas em um banco de dados. Para o GF, foi elaborada a seguinte questão norteadora: Quais foram as contribuições das oficinas pedagógicas para seu papel de interlocutor da EPS na instituição de saúde de seu município?

As informações provenientes do GF foram submetidas à análise temática de conteúdo ${ }^{(16)} \mathrm{e}$ interpretadas à luz da Pedagogia Crítica Freiriana ${ }^{(9,14,17)}$. Assim, na pré-análise as informações foram organizadas e lidas com atenção. Na sequência, durante o processo de exploração do material, foram selecionados os trechos das falas significativas, quando se realizou o tratamento, a inferência e a interpretação dos resultados, o que permitiu a 
construção final de duas categorias temáticas intituladas: "Do tempo do verbalismo e ativismo ao ato consciente na Educação Permanente em Saúde" e "Da obstinação do método tradicional de ensino às ações em EPS com método ativo".

O projeto foi apreciado e aprovado por Comitê de Ética em Pesquisa, CAAE: 63161816.8.0000.5393, e todos participantes assinaram o Termo de Consentimento Livre e Esclarecido.

\section{RESULTADOS E DISCUSSÃO}

\section{Caracterização sociodemográfica e profissional dos interlocutores}

O grupo foi constituído por 15 interlocutores, sendo 14 (93,33\%) do sexo feminino, com média de 42 anos de idade. Em relação ao grau de escolaridade, 11 (73,33\%) possuem graduação e algum curso de especialização na área da saúde. No que tange ao tempo de serviço, a média foi de 17 anos, dentre os quais 12 (80\%) trabalham na área hospitalar, dois (13,33\%) no DRS e um (6,66\%) na Atenção Primária à Saúde. Dentre os participantes, cinco (33,33\%) são enfermeiras, além de duas técnicas de enfermagem, duas pedagogas, uma dentista, uma administradora, uma assistente social, uma farmacêutica, uma professora e um técnico de informática. Quando questionados sobre o envolvimento na área da Educação, 11 (73,33\%) interlocutores já haviam realizado algum curso na área e $13(86,66 \%)$ já ministraram ao menos um curso ou palestra em sua trajetória profissional.

Definir o perfil do grupo possibilita a compreensão do contexto em que o participante está inserido e também orienta as escolhas pedagógicas do mediador ${ }^{(18)}$, tais como: a complexidade das exposições e dos textos científicos, a amplitude dos estudos de caso, a organização e hierarquização de conceitos com proposições nos mapas conceituais e as articulações nas sínteses do conhecimento com os possíveis aportes teóricos.

A concentração de profissionais formados em enfermagem nesta pesquisa também foi verificada em estudo que analisou as percepções de tutores e facilitadores sobre o curso de facilitadores de EPS $^{(19)}$. Entretanto, coaduna-se com o argumento de que a presença de outras categorias contribuiu para diversificar o compartilhamento de experiências com olhares diferentes, o que possivelmente favorece o diálogo e a compreensão da realidade e potencializa a busca por intervenções inclusivas e integradas ${ }^{(20)}$.

\section{Do tempo do verbalismo e ativismo ao ato consciente na educação permanente em saúde}

Esta categoria caracteriza-se pelas falas que refletem sobre os avanços que as OP possibilitaram na articulação entre teoria e prática na EPS ou, mais propriamente, pela concretude revelada a partir do compartilhamento de experiências e conhecimentos necessários para fundamentar a EPS, aquela que acontece no trabalho e pelo trabalho. Freire alerta para o fato de que a teoria isolada é puro verbalismo: são palavras que ecoam sem sentido no contexto a ser transformado, porque apenas foram ditas ${ }^{(9)}$. Constituem informações não valorizadas porque não encontraram a reflexão na ação. Por outro lado, a prática desprovida de fundamento aliena-se no ativismo pragmático. No entanto, é na integração consciente entre a prática e a teoria que se dá a práxis, a ação criadora e transformadora de seus atores e da realidade em que vivem. Esses extremos coexistem num cenário educacional em que prevalece a aprendizagem mecânica, desarticulada do diálogo reflexivo sobre as ações que ocorrem num determinado tempo e realidade local ${ }^{(14,17)}$. 
Os princípios da EPS procuram garantir a articulação entre a teoria e a prática(1), assim as OP devem reproduzir a essência da construção de novos conhecimentos pelo diálogo proveniente da experiência dos participantes e dos investimentos na análise das situações problema sustentadas por referencial teórico-

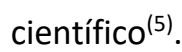

A interlocução teoria-prática dos temas desenvolvidos - uma das potencialidades discutidas no GF ocorreu de forma que os participantes/interlocutores trouxessem as dificuldades para as oficinas e, junto ao grupo, discutissem os problemas enfrentados, o que, segundo os participantes, possibilitou mudança das ações desenvolvidas na prática do trabalho, como se nota nas falas abaixo:

P1: [...] uma potencialidade foi a gente trabalhar com o formato que teve, então a gente teve que elencar com a prática e depois dar a devolutiva aqui [...] a partir daquele momento começou a alavancar um monte de alternativas que também a gente poderia implementar lá dentro do hospital [...], fazer aqui, levar pra prática dentro do nosso serviço e depois dar um feedback do que aconteceu.

P15: foi a primeira vez, as oficinas, que se torna palpável [...], pra mim fez muito sentido. Traz o artigo, a gente debate, como aplicar na prática, é isso. Vocês trouxeram coisas, trazem uma bagagem pra gente poder usar no dia a dia, não ficou no teórico. Pra mim, é uma coisa construtiva.

Essa compreensão da dinâmica da aprendizagem fundamentada na ação-reflexão-ação deu-se ao passo em que os participantes/interlocutores começaram a notar a importância da reflexão crítica como um disparador para (res)significar o processo de trabalho. Freire aponta que "o próprio discurso teórico, necessário à reflexão crítica, tem de ser de tal modo concreto que quase se confunde com a prática”(9).

A aprendizagem crítica de Freire faz um convite à recusa ao ensino bancário, caracterizado por um ensino de transferência de informações e existência de um aprendiz não contestador. Essa aprendizagem freireana recomenda a adesão ao ensino problematizador, que requer que os educadores e educandos façam-se criativos, instigadores, inquietos, rigorosamente curiosos e persistentes ${ }^{(1,5,14)}$.

Para isso, torna-se imprescindível o uso de metodologias ativas que possibilitem uma aprendizagem significativa, por meio das quais se façam úteis as vivências dos interlocutores, proporcionando a problematização de suas respectivas práticas ${ }^{(21)}$.

Diante desse cenário, as OP propiciaram avanços no papel de educador dos participantes/interlocutores da EPS, posto no GF por meio do reconhecimento da problemática do trabalho e da responsabilidade do trabalhador em seu próprio processo de aprendizagem, o que mostrou a compreensão da importância do trabalho em equipe na educação permanente em saúde, como desvelado nas falas abaixo:

P13 o que as oficinas têm colaborado muito é conhecer principalmente as dificuldades e a problemática mesmo [...] De onde vem o problema, o que gera aquilo e quais são as pessoas envolvidas e qual a forma de abordagem, o que é muito interessante. Então, hoje, a gente vê que inserir o colaborador na resolutiva do problema dele é fundamental, porque ele consegue ter uma compreensão diferenciada daquilo que foi um erro, mas que, às vezes não só dele, de outras pessoas envolvidas, e ele se sente capaz de aprimorar aquilo.

P8: Todos passam a ser responsáveis de fato por aquele processo, então, assim, se um não tiver inteiramente conjugado com aquele trabalho, aquele processo não acontece da forma que precisaria acontecer.

Freire acredita que o educando tem que ser protagonista do seu processo de aprendizagem ${ }^{(17)}$. Quando o processo educativo está alicerçado na prática, os sujeitos participam de uma reflexão libertadora do processo de 
trabalho, que oriunda da desalienação dos trabalhadores e propõe a transformação de si e da sociedade ${ }^{(14-17)}$. No âmbito do Sistema Único de Saúde (SUS), o processo de mudança na educação requer a participação coletiva e democrática, já que os sujeitos estão interligados em rede. Assim, a reflexão, o diálogo e o reconhecimento da realidade e das problemáticas são peças-chave para a busca pela integralidade da educação na saúde(22).

A existência de trabalhadores corresponsabilizados com a causa possibilita o olhar para o mundo e para a condição humana de forma conjunta, o que viabiliza a transformação da realidade. Dessa maneira, é fundamental que os trabalhadores da saúde sejam críticos quanto às problemáticas do trabalho e busquem a ferramenta da EPS no intuito de alicerçar uma melhor qualidade de trabalho e ações em saúde, em prol do usuário do SUS ${ }^{(17,22)}$.

\section{Da obstinação do método tradicional de ensino às ações em EPS com método ativo}

A obstinação da metodologia tradicional de ensino pelos indivíduos ainda é uma grande barreira a ser desmantelada na EPS e uma dificuldade apresentada pelos participantes/interlocutores, principalmente nos momentos em que assumem a frente de um grupo em sua instituição de trabalho, tal como exemplificado na fala abaixo:

P9 É porque já está incorporada a metodologia de ensino, todos nós aqui, nós não tivemos a metodologia ativa, nosso conhecimento foi passado de outra maneira: o professor passava pra gente. Então, a minha grande dificuldade é nesse ponto.

A hegemonia da formação tradicional em saúde, historicamente marcada pela metodologia clássica de ensino, também foi encontrada em estudo na literatura no que diz ao estranhamento dos discentes de uma universidade de enfermagem quando deparados com métodos ativos de ensino ${ }^{(23)}$. Segundo os autores, isso ocorreu porque os estudantes estavam acostumados com outras formas de aquisição de conhecimento que não o diálogo. Além disso, muitos alunos mostraram-se inseguros para desenvolverem atividades de forma mais livre e sem a necessidade de aulas teóricas. Com os interlocutores da EPS do presente estudo, além dessa acomodação subsidiada pelo método tradicional de ensino, verificou-se também fatores como a desmotivação da equipe, a dinamicidade das instituições hospitalares e a falta do apoio do gestor da unidade, fatores estes que dificultam a utilização do método ativo de aprendizagem e a própria realização da Educação Permanente em Saúde. Essa dificuldade dos interlocutores em construir uma prática educativa com método ativo deve-se ao seu percurso formativo pautado no método tradicional que, por vezes, determina suas escolhas didáticas ${ }^{(1,4,19)}$.

Apesar da prática pedagógica inovadora caracterizar-se como "o novo" e "o desconhecido", pode parecer aos indivíduos uma ameaça às concepções de educação historicamente construídas ao longo de suas vidas. Importante destacar, contudo, que esse desconhecimento dificulta a concepção de novos horizontes e impossibilita transformações ${ }^{(17)}$. Ademais, tem-se a falsa crença de que o processo de aprendizagem ocorre somente em ambientes formais e pontuais, o que pode levar a rotular o processo ativo de aprendizagem como algo sem seriedade. Nesse sentido, é importante que os trabalhadores da saúde compreendam que o ser humano produz conhecimento e desenvolve competências ao longo da vida toda, sempre que compartilha ideias e valores $^{(20,22)}$. 
Para que ocorra a transformação desse cenário na saúde, é preciso que os métodos de ensino sejam transformados, provocando a construção de novos saberes e fazeres ${ }^{(20)}$. Isso ocorre porque a prática da educação mais dialógica colabora para a formação de profissionais mais humanos e mais preocupados com a realidade e com a transformação social.

Ao passo que as oficinas foram acontecendo, observou-se um avanço na compreensão dos interlocutores acerca do conceito de metodologia ativa de ensino-aprendizagem e de suas potencialidades para a formação do trabalhador da saúde.

P3 ...é que a ativa é quando a gente insere aquelas pessoas [...] elas passam a ser parte daquele processo, todo mundo trabalha junto, discute juntos, formula soluções juntos; e quando é... a passiva, aí já é um processo só de transferência.

Essa compreensão, ao longo das oficinas, permitiu que os interlocutores iniciassem projetos e intervenções em seus locais de trabalho, inserindo o método ativo na realidade dos trabalhadores.

P2 [...] é que sempre eles ficavam sempre na parte passiva, né? la na nossa salinha de treinamento e aí dava pra ver que uns dormiam e hoje já não. A gente tá trazendo eles para a discussão também, pros testes, pros procedimentos, o que fazer com o paciente, acho que isso foi bem legal [...] facilitou com um trabalho que a gente começou que é o On the Job, que é você ir até o local de trabalho e tentar trabalhar com essa parte realmente da metodologia ativa. Eu acho que as oficinais foram muito importantes pra gente.

É notório que a educação de nível superior pautada no uso de metodologias ativas tem um maior potencial na formação dos profissionais da saúde quando comparada àquelas que adotam metodologias tradicionais, devido à sua capacidade de formar profissionais mais preparados para atender às necessidades atuais de saúde ${ }^{(23)}$. Percebe-se, no presente estudo, que isso se deve à potencialidade dos métodos ativos em construir a criticidade e reflexão dos interlocutores, auxiliando-os tanto no próprio exercício da profissão, como no papel de interlocutor, à frente de grupos, na construção do conhecimento.

Nesse contexto, ressalta-se que a educação permanente em saúde é crucial, uma vez que o trabalhador permanece poucos anos na faculdade ou ensino técnico, sendo sua maior atuação na prática. Esse ensino no cotidiano do trabalho não pode mais acompanhar os moldes teóricos e não dialógico. Assim, faz-se necessária a formação de um profissional ativo e apto a aprender a aprender ${ }^{(24)}$, que ocorre por meio da aprendizagem problematizadora.

\section{CONSIDERAÇÕES FINAIS}

Este estudo evidenciou as contribuições das oficinas pedagógicas na construção de novos saberes para prática do interlocutor da educação permanente em saúde. Ao final das atividades, pôde-se notar que as oficinas possibilitaram articulação entre teoria e prática na EPS, o compartilhamento de experiências e de conhecimentos necessários para fundamentar essa estratégia educativa, além de instigar a mudança das ações desenvolvidas na prática do trabalho. As metodologias diversificadas utilizadas nas oficinas permitiram aos participantes vivenciarem exemplos práticos de como os métodos ativos de aprendizagem fundamentados na teoria de Paulo Freire podem ser incorporados às ações de EPS. Nesse sentido, considera-se que as OP foram um espaço artesanal, 
com tempo-espaço para síntese do pensar, sentir e agir do interlocutor/participante da pesquisa da EP, que potencializou a reflexão sobre o conhecimento de seus pressupostos e sobre a vida.

As limitações que envolvem as OP decorrem das dificuldades encontradas pelo interlocutor em obter o reconhecimento da EPS no município de sua origem ao planejar a continuidade do processo, devido à compreensão ainda equivocada da gestão sobre a PNEPS como ações de educação continuada. A partir dessa perspectiva, a cooperação entre as instituições de ensino e de saúde carecem de fortalecimento político e financeiro, com o apoio da gestão municipal e estadual para a vital disseminação da EP. Outras pesquisas com intervenções em contextos diversos também são esperadas para o seu desenvolvimento, ao qualificarem os resultados e fomentarem as transformações desejadas na qualificação dos profissionais, do processo de trabalho e da gestão para cuidado em saúde.

\section{REFERÊNCIAS}

1. Mello AL, Backes DS, Terra MG, Rangel RF, Nietsche EA, Salbego C. (Re) pensando a educação permanente com base em novas metodologias de intervenção em saúde. Revista Cubana de Enfermería. 2017;33(3):1-13.

2. Sadeghnezhad M, Nabavi FH, Najafi F, Kareshki H, Esmaily H. Mutual benefits in academic-service partnership: An integrative review. Nurse Education Today. 2018;68:78-85.

3. Andrade SR, Boehs AE, Mattia D, Boehs CGE, Daussy MFS. Cooperação e relacionamento entre instituições de ensino e serviço de saúde: o pró-saúde enfermagem. Texto Contexto Enferm. 2014;23(1):160-6.

4. Miccas FL, Batista SHSS. Educação permanente em saúde: metassíntese. Rev. Saúde Pública [online]. 2014;48(1):170-85.

5. Peres C, Silva RF, Barba PCSD. Desafios e potencialidades do processo de educação permanente em saúde. Trabalho, Educação e Saúde. 2016;14(3):783-801.

6. Senna MCM, Arantes RF, Wiese ML. O processo de implementação da Política Nacional de Educação Permanente em saúde. In: Anais do 4을 Encontro Internacional de Política Social/11o Encontro Nacional de Política Social, 2016, Vitória, Brasil [Internet]. 2016. [acesso em: 30 abr 2017]. Disponível em: http://periodicos.ufes.br/EINPS/article/view/12933/9314.

7. Cardoso MLM, Costa PP, Costa DM, Xavier C, Souza RMP. A Política Nacional de Educação Permanente em saúde nas Escolas de Saúde Pública: reflexões a partir da prática. Ciênc. saúde colet. 2017;22(5):1489-1500.

8. Moita FM, Andrade FCB. O saber de mão em mão: a oficina pedagógica como dispositivo para a formação docente e a construção do conhecimento na escola pública. In: Anais Educação, Cultura e Conhecimento na contemporaneidade: desafios e compromissos, 2006, Caxambu, Brasil [Internet]. 2006. [acesso em: 12 jun 2018]. Disponível em:

http://www.anped.org.br/sites/default/files/gt06-1671.pdf.

9. Freire P. Pedagogia da autonomia: saberes necessários à prática educativa. 53a ed. São Paulo: Paz e Terra; 2016.

10. Candau VM, Zenaide MNT, Melo JAPM. Oficinas aprendendo e ensinando Direitos Humanos. João Pessoa: Programa Nacional de Direitos Humanos; Secretaria da Segurança Pública do estado da Paraíba; Conselho Estadual da Defesa dos Direitos do Homem e do Cidadão; 1999.

11. Rückert B, Machado AR, Santos CCA, Brito PCD. (2014). Diálogos entre a Saúde do Campo e a Saúde Mental: a experiência da Oficina de Educação Popular em Saúde Mental do MST na ESP MG. Interface - Comunicação, Saúde, Educação. 2014;18(Suppl 2);1537-46.

12. Glowacki-Dudka M, Ward A. Understanding popular education and arts based learning within groups through a peace workshop. Adult Education Research Conference, 2018 June 7-10, Victoria; Canada; 2018.

13. Campos DS, Turci MA, Melo EM, Guerra VA, Nascimento CGM, Moreira CA, et al. Construção participativa da Política Estadual de Promoção de Saúde: caso de Minas Gerais, Brasil. Ciênc. saúde colet. 2017:22(12);3955-64.

14. Rozendo CA, Salas AS, Cameron B. Problematizing in nursing education: Freire's contribution to transformative practice. Nurse Education Today. 2017;51:120-3.

15. Barbour R. Grupos focais. Porto Alegre: Artmed; 2009.

16. Bardin L. Análise de Conteúdo. São Paulo: Edições 70; 2011.

17. Fernandes S. Pedagogia crítica como práxis marxista humanista: perspectivas sobre solidariedade, opressão, e revolução. Educ. Soc. 2016;37(135):481-96.

18. Mendonça FF, Nunes EFPA, Garanhani ML, González AD. Avaliação de tutores e facilitadores sobre o processo de formação de facilitadores de Educação Permanente em Saúde no município de Londrina, Paraná. Ciênc. saúde colet. 2010 [acesso em: 12 mar 2017];15(5):2593-2602. Disponível em: http://dx.doi.org/10.1590/S1413-81232010000500033. 
19. Maia FES, Evangelista AIB. A Educação Permanente em Saúde: compartilhamento de saberes, modificação da realidade. Interdisciplinaridade. Revista do Grupo de Estudos e Pesquisa em Interdisciplinaridade. [Internet] 2015 [acesso em: 10 mar 2017];(7):16-25. Disponível em: https://revistas.pucsp.br/index.php/interdisciplinaridade/article/view/25065.

20. Prado ML, Velho MB, Espíndola DS, Sobrinho SH, Backes VMS. Arco de Charles Maguerez: refletindo estratégias de metodologia ativa na formação de profissionais de saúde. Escola Anna Nery. 2012;16(1);172-7.

21. Mitre SM, Siqueira-Batista R, Girardi-de-Mendonça JM, Morais-Pinto NM, Meirelles CAB, Pinto-Porto C, et al. Metodologias ativas de ensino-aprendizagem na formação profissional em saúde: debates atuais. Ciênc. saúde colet. 2008;13(2):2133-44.

22. Silva LAA, Ferraz F, Lino MM, Backes VMS, Schmidt SMS. Educação permanente em saúde no trabalho de enfermagem: perspectiva de uma práxis transformadora. Rev Gaúcha Enferm. 2010 set;31(3):557-61.

23. Fujita JALM, Carmonaii EV, Shimoiii AKK, Mecenaiv EH. Uso da metodologia da problematização com o Arco de Maguerez no ensino sobre brinquedo terapêutico. Rev. Portug. Educ. 2016;29(1):229-58.

24. Oliveira RCS, Galavote HS, Lima RCD, Lima EFA. Práticas educativas para os trabalhadores da Estratégia Saúde da Família. Rev Bras Pesq Saúde. 2017;18(1):120-9. 